\title{
Analysis of thermal resistance evolution of ash deposits during co-firing of coal with biomass and coal mine waste residues
}

\author{
B. Peña, C. Bartolomé, A. Gil \\ Centre of Research for Energy Resources and Consumption (CIRCE) C/Mariano Esquillor Gómez, 15, 50018 \\ Zaragoza, Spain
}

\begin{abstract}
Co-firing biomass or waste fuels with coal in conventional thermal plants is a promising way to reduce environmental impact of human activities with an acceptable economic investment. One of the main issues to be addressed is the worsening in ash fouling and the reduction of heat transfer rate. In the present paper, the deposits thermal resistance during direct combustion of different blends of coal and various native fuels is investigated by using a deposition probe, kept at $550{ }^{\circ} \mathrm{C}$ in order to emulate the conditions of superheaters of conventional power units. Two energy crops (Cynara cardunculus L. and Populus spp.), a forest residue (Pinus pinaster) and a waste coal (coal mine waste residues)
\end{abstract} were successfully tested in a semi-industrial scale pilot plant.

A thermal model of the probe is presented to estimate heat transfer rate and thermal resistance of ash deposits. After the validation with experimental data, a sensitivity analysis allows to identify the deposit surface emissivity and the flue gas temperature as the most influential parameters. The heat uptake in air flow decreases with time for all the experimental tests in spite of the increase in flue gas and walls temperatures. Except for poplar blends, under similar operation conditions, a rise in the substitution percentage means faster decreasing rates in heat transfer and higher thermal resistance due to the ash deposits, especially for cynara and coal mine waste residues.

The present work demonstrates the usefulness of thermal models to estimate the thermal resistance of ash deposits without the need of sophisticated instrumentation. Dedicated thermal models, similar to the developed one, could serve to design smart cleaning sequences to improve efficiency in power generation processes. 
Promoted by diverse international energy policies, biomass and other low-cost fuels, as coal mine waste residues, emerge as promising native resources, which can be co-fired with coal in existing power plants to reduce external energy dependency and environmental impacts.

Biomass, considered a renewable and $\mathrm{CO} 2$-neutral resource, continues to attract great attention because of the priority to reduce greenhouse and pollutant emissions $(1 ; 2 ; 3)$. In 2009, the IEA Bioenergy Implementing Agreement identified globally some 150 power plants using coal along with biomass, mainly located in nothern Europe and in the United States, and it is expected an important increase in the next decade (4).

Coal mine waste residue (CMR) is a much less conventional fuel coming from low-energy-value discards of the coal mining industry. Usually, coal mine waste residues pile accumulated near the original mines as a potential source of environmental pollution. There exists around 30 coal mine waste residues burning power plants in the United States, all of them based on Circulanting Fluidized Bed technology (5). However, as the $90 \%$ of thermal power stations in the world are based on pulverized fuel burners, research on co-firing of CMR under such technology is very desirable.

Ash deposition on heat transfer surfaces during combustion brings about significant losses of efficiency in large solid-fired boilers $(6 ; 7)$, long-term corrosion and even boiler shut-down $(1 ; 8 ; 9)$. These problems become more critical for biomass and coal mine waste residues, as the former usually have high concentrations of alkali metals, sulfur and chlorine (10), and the later might be constituted by a $50 \%$ of ash matter, including iron, manganese or sulfur.

A lot of research has been done aiming at the modelling of deposits growth from different approaches: definition of slagging indices $(11 ; 12 ; 13)$, direct simulation by Montecarlo method (14), or CFD models $(15 ; 16 ; 17 ; 18 ; 19 ; 20 ; 21)$. This kind of models results of great interest to understand the relative importance of the processes involved in ash deposition, to have an insight of the slagging potential of new fuels and to optimize the design of boilers and heat transfer exchangers. Nevertheless, such models involve many empirical parameters that introduce important uncertainties which limit the accuracy of predictions in actual power boilers.

Ash deposition strongly depends on the nature of the coal mineral matter, but also on particle size and shape $(15 ; 22)$ and working temperatures $(23 ; 24 ; 25)$. Those parameters are crucial for growth rate, sintering processes and microstructure of deposits $(24 ; 26)$. Therefore, they determine the thermal properties of the formed deposits, namely thermal conductivity and emissivity $(6 ; 26 ; 27$; $28 ; 29 ; 30$ ), which are essential in heat transfer processes. However, experimental results on deposit 
Abbreviations

SAC South African Coal

CYN Cynara Cardunculus

PWO Pine Wood Chips

POP Poplar Populus ssp.

CMR Coal Mine (Waste) Residues

w.b. wet basis

d.b. dry basis

SCADA Supervisory Control and Data Acquisition HHV High Heating Value

Geometrical parameters

D diameter $(\mathrm{m})$

A $\quad$ area $\left(\mathrm{m}^{2}\right)$

$r \quad$ radius $(\mathrm{m})$

$x \quad$ length of a section $(\mathrm{m})$

Radiative model

$\epsilon \quad$ emissivity

$\alpha \quad$ absortivity

$R_{k} \quad$ resistance by emission of $\mathrm{k}\left(\mathrm{m}^{-2}\right)$

$R_{k l} \quad$ resistance between $\mathrm{k}$ and $\mathrm{l}\left(\mathrm{m}^{-2}\right)$

$R_{k k} \quad$ equivalent resistance for $\mathrm{k}\left(\mathrm{m}^{-2}\right)$

$J \quad$ node radiosity $\left(\mathrm{W} / \mathrm{m}^{2}\right)$
Thermal model

$T \quad$ temperature $(\mathrm{K})$

cp specific heat capacity $(\mathrm{J} / \mathrm{kg}-\mathrm{K})$

$h$ convection coefficient $\left(\mathrm{W} / \mathrm{m}^{2}-\mathrm{K}\right)$

$\dot{m} \quad$ cooling air mass flow $(\mathrm{kg} / \mathrm{s})$

$R_{t}^{\prime} \quad$ thermal resistance per unit lenght $(\mathrm{m}-\mathrm{K} / \mathrm{W})$

$\dot{Q} \quad$ heat transfer rate $(\mathrm{W})$

Subscripts

ch combustion chamber

dep deposit

0 inner surface of inner duct

1 outer surface of inner duct

2 inner surface of outer duct

3 inner surface of inner duct

$j$ control volume $\mathrm{j}$ of deposition probe

cw $\quad \mathrm{H}_{2} \mathrm{O} / \mathrm{CO}_{2}$ mixture

$s \quad$ deposit surface

$w \quad$ water wall

$g \quad$ flue gases

air cooling air

a air flux in the annulus

$i \quad$ internal air flux

$k, l, m \quad$ referred to $s, w, g$

thermal properties are quite scarce, very dependent on fuel blends and usually require specific and complex instrumentation $(24 ; 31 ; 32 ; 33 ; 34)$.

In spite of the great interest of these research works, the complexity of the required measurement 
equipment and the involved mathematical methods could jeopardize its practical usefulness for online monitoring or control systems under actual conditions. With this goal in mind, it is necessary to develop simplified models based on usually available plant data $(35 ; 36)$.

The present paper is focused on co-firing of different fuel blends in a semi-industrial scale pilot plant provided with an air-cooled deposition probe. The objectives of the work are threefold: (i) to present experimental results about successful co-firing of coal mine waste residues in a pulverized fuel burner for the first time in the literature; (ii) to estimate the deposits thermal resistance through the development of a thermal model, as a quantitative parameter to be used in eventual soot-blowing strategies (iii) to compare the thermal resistance evolution for different blends of biomass and coal mine waste residues.

The main novelties of the work, besides the use of CMR as fuel, are the improvement of the radiation model with respect to previous papers $(35 ; 36)$, considering two sink surfaces and a gaseous source, and the simplified modelling approach with few data available in actual power boilers.

The experimental facility and the tests program is presented in Section 2. The thermal model to estimate fouling thermal resistances is detailed and validated in Section 3. The main results of the work are gathered in Section 4: experimental data acquired during co-firing tests, a sensitivity analysis to identify the main influential parameters on predicted thermal resistances and the comparison of results for different fuel blends.

\section{Experimental methodology}

\subsection{Combustion pilot plant}

The experimental facility consists of a $500 \mathrm{~kW}_{\text {th }}$ swirl burner for pulverized fuel, placed downward on top of a cylindrical chamber $3 \mathrm{~m}$ long and $1 \mathrm{~m}$ of internal diameter (Figure 1). The combustion chamber comprises six water-cooled rings, being the three in the upper part coated with refractory concrete to promote flame stability. The swirl burner includes an ignitor of natural gas of $35 \mathrm{~kW}_{\text {th }}$ and two concentric entries of primary air-fuel and secondary air streams. Swirl is imposed by a tangential scroll to the primary air while the secondary air crosses an externally controlled system of radial vanes, located on the bottom of a wind box. An air-cooled cross-flow heat exchanger of 47 tubes is placed at the middle of the combustion chamber in order to investigate corrosion and degradation. 


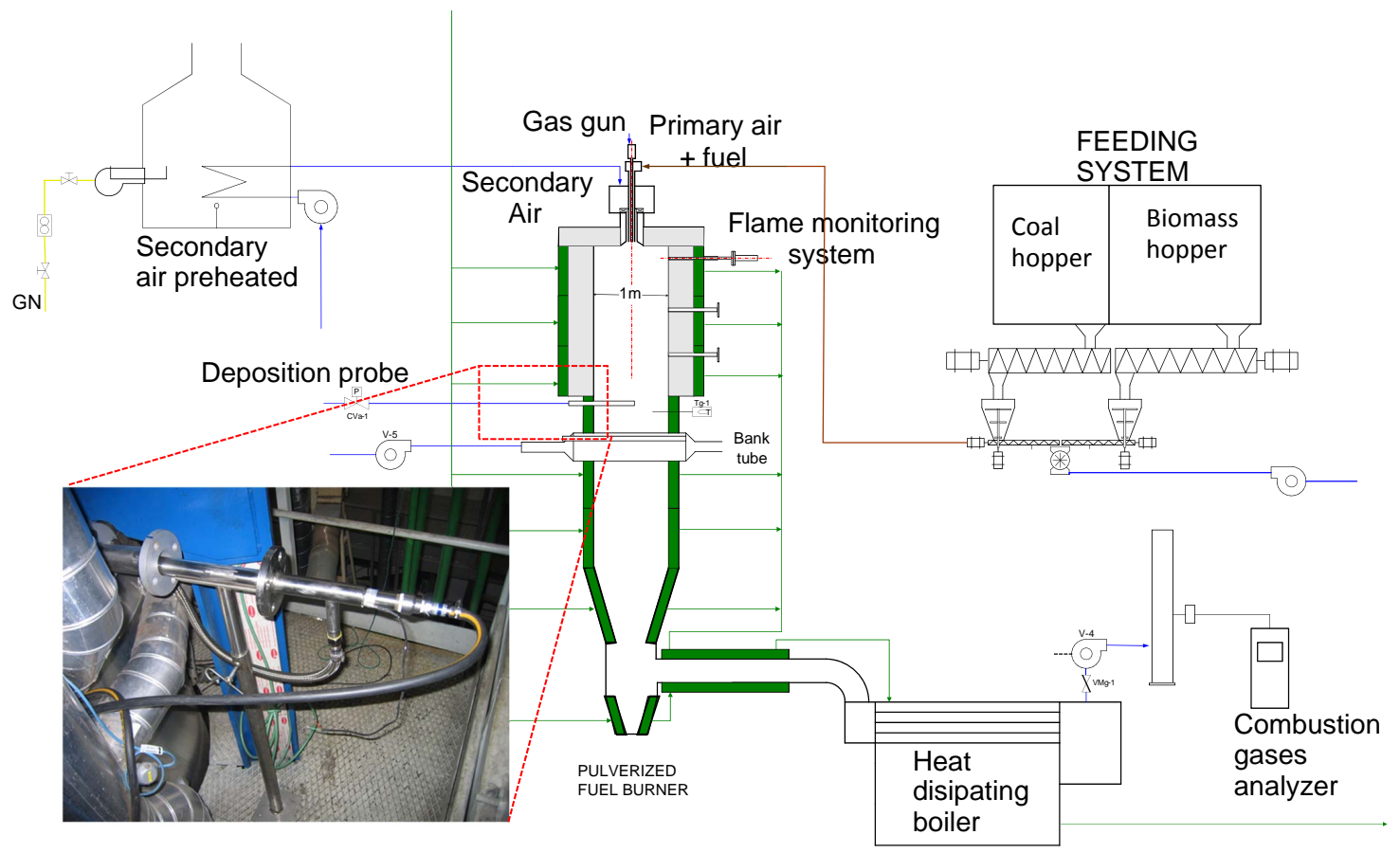

Figure 1: Arrangement of the combustion test facility and deposition probe locatetion.
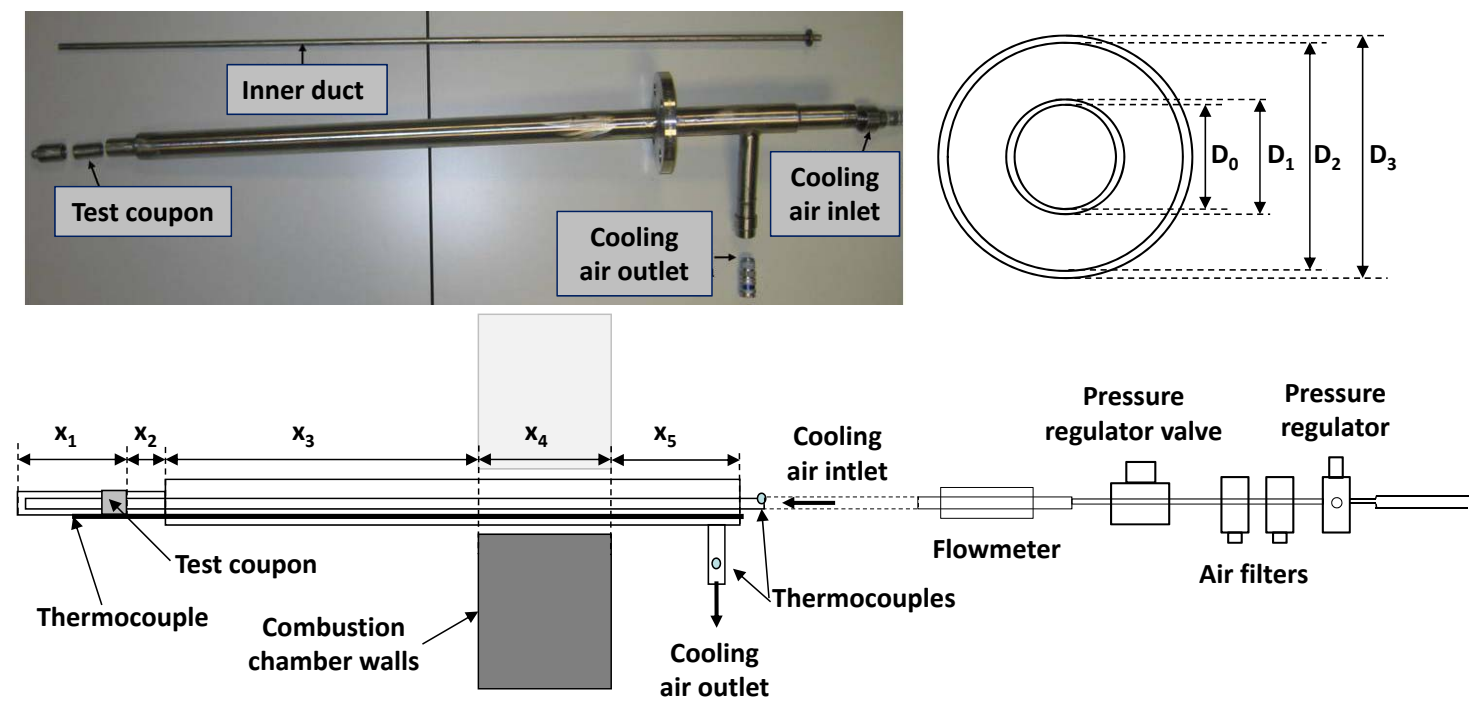

Figure 2: Layout of the deposition probe. 
Table 1: Characterization of fuels. The oxygen concentration has been calculated by difference.

\section{SAC POP CYN PWO CMR}

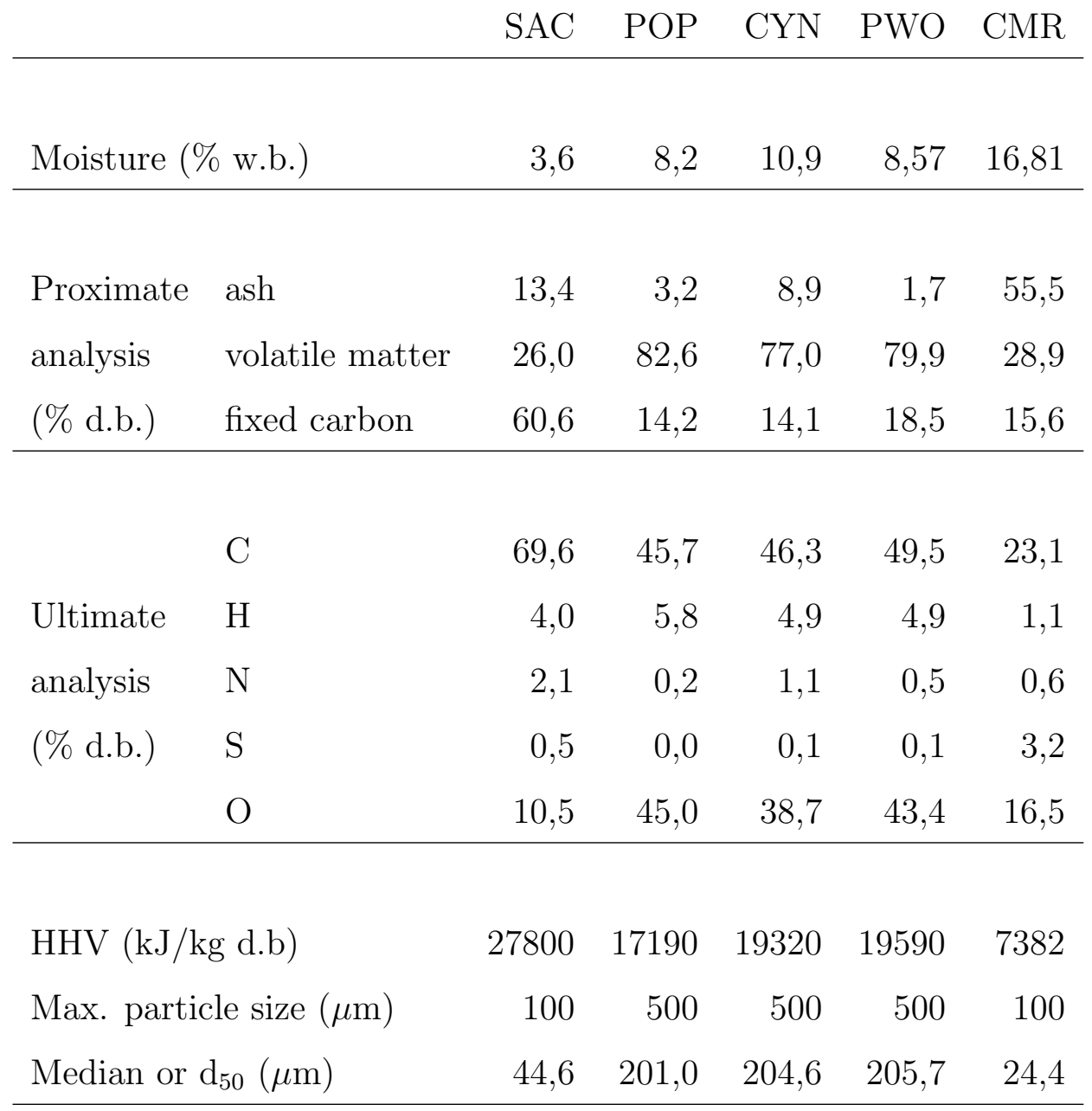

Thermocouples measure water temperatures at inlet and outlet of each water ring, air temperature at inlet and outlet of tube bank, temperature of 12 points into the refractory walls, and flue gas temperature just below the refractory rings inside the furnace. Different flow meters register the flow rate of the cooling water and the air flow of primary, secondary and tube bank cooling streams. Concentration of main species present in flue gases $\left(\mathrm{CO}, \mathrm{CO}_{2}, \mathrm{O}_{2}, \mathrm{SO}_{2}, \mathrm{NO}\right)$ is continuously measured with a complete set of standard analyzers. An advanced SCADA system (Supervisory Control and Data Acquisition) provides the on-line control, visualization and recording of operation parameters and emissions. Further details of the experimental facility can be found in $(37 ; 38 ; 39)$.

Finally, a visualization system based in a CCD camera (charged coupled device) is used to monitor continuously the flame and to acquire videos when it is needed. The CCD camera inside a protective probe is installed at the first refractory ring of the combustion chamber in order to register the root of the flame. Details of the equipment and analysis procedure can be found in Ref. (40). The flame 
videos will be useful in the present work to identify anomalous combustion states and to interpret the experimental observations.

\subsection{Deposition probe}

A deposition probe inserted in the combustion chamber was used to investigate ash deposits formation during the combustion of different fuel blends $(37 ; 41)$. The surface probe is kept at a constant temperature of $550 \pm 5^{\circ} \mathrm{C}$ to reproduce the typical operating temperatures of superheaters of thermal power units. It is inserted in a spyhole located at $1.7 \mathrm{~m}$ from the burner throat, just above the cross-flow heat exchanger.

The probe is cooled by pressurized air which flows inside two stainless-steel concentric pipes. Air enters into the inner duct at ambient temperature coming from a compressor and returns by the external annular pipe. Figure 2 gathers the geometrical parameters of the probe, including the nomenclature used in the following sections. The external diameter $\left(D_{3}\right)$ is $40 \mathrm{~mm}$ and the total length inside the combustion chamber $515 \mathrm{~mm}$.

The deposition probe is instrumented with an air-flow meter for the inlet of cooling air and three thermocouples for the measurement of the outer surface temperature near the test coupon and the inlet and the outlet cooling air temperatures. The surface temperature is adjusted by a control loop programmed in a PLC (Programmable Logic Controller) by adjusting the cooling air flow rate with an automatic control valve (42).

\subsection{Fuel blends}

Experimental tests were performed with different blends of bituminous South African coal (SAC) and several native solid fuels: three biomasses (Cynara cardunculus L.-CYN, Populus spp.-POP and Pinus pinaster-PWO) and coal mine waste residues (CMR) of very low heating value (HHV). Preprocessing of samples and characterization analyses agree international normative and details can be found in previous works (41). The main characteristics of the tested fuels are summarized in Table 1.

With respect to biomasses, PWO and CYN have similar heating values, slightly higher than POP. Moisture and specially ashes are higher for CYN, while volatile matter, which favors ignition, is lower than that of POP and PWO. Some previous works studied the ash composition with SEM/EDS (Energy Dispersive X-ray Spectroscopy) and ICP-OES (Inductive Coupled Plasma-Optical Emission Spectroscopy) techniques (41).

Regarding CMR, it has to be noted its very low heating value, the high ash content and the low content on carbon and hydrogen. Given the intrinsic difficulties related to coal mine waste residues 
Table 2: Operation parameters during experimental tests during co-firing of SAC and CYN, PWO, POP or CMR. (*) Measurement of flue gas by a thermocouple before correction.

\begin{tabular}{|c|c|c|c|c|c|}
\hline Test Code & 1 & 2 & 3 & 4 & 5 \\
\hline$\%$ substitution & $0 \%$ & $5 \% \mathrm{CYN}$ & $10 \% \mathrm{CYN}$ & $15 \% \mathrm{CYN}$ & $10 \% \mathrm{PWO}$ \\
\hline Coal mass flow rate $(\mathrm{kg} / \mathrm{h})$ & 68.4 & 65.0 & 61.6 & 58.2 & 61.6 \\
\hline Biomass mass flow rate $(\mathrm{kg} / \mathrm{h})$ & 0 & 6.2 & 12.3 & 18.5 & 10.2 \\
\hline Primary / Secondary air & 0.30 & 0.29 & 0.32 & 0.32 & 0.34 \\
\hline Excess of air (\%) & 19 & 25 & 20 & 19 & 13 \\
\hline Mean flue gas temperature* $\left({ }^{\circ} \mathrm{C}\right)$ & 940 & 970 & 920 & 935 & 947 \\
\hline Refractory wall temperature $\left({ }^{\circ} \mathrm{C}\right)$ & 445 & 465 & 413 & 481 & 475 \\
\hline Test Code & 6 & 7 & 8 & 9 & 10 \\
\hline$\%$ substitution & $10 \% \mathrm{CYN}$ & $10 \% \mathrm{POP}$ & $15 \% \mathrm{POP}$ & $10 \% \mathrm{CMR}$ & $20 \% \mathrm{CMR}$ \\
\hline Coal mass flow rate $(\mathrm{kg} / \mathrm{h})$ & 61.6 & 61.6 & 58.17 & 61.8 & 54.9 \\
\hline Secondary fuel mass flow $(\mathrm{kg} / \mathrm{h})$ & 11.2 & 11.3 & 16.9 & 27.2 & 54.3 \\
\hline Primary / Secondary air & 0.35 & 0.34 & 0.36 & 0.33 & 0.41 \\
\hline Excess of air (\%) & 11 & 11 & 11 & 34 & 40 \\
\hline Mean flue gas temperature* $\left({ }^{\circ} \mathrm{C}\right)$ & 961 & 962 & 985 & 1011 & 1059 \\
\hline Refractory wall temperature $\left({ }^{\circ} \mathrm{C}\right)$ & 587 & 585 & 707 & 455 & 642 \\
\hline
\end{tabular}

combustion, no previous works were found by the authors in the literature and new research must be done.

\subsection{Test series}

Experimental tests were performed in several series, whose details are gathered in Table 2, including percentages of fuels in energy basis, mean mass flows and mean temperature of flue gases and refractory walls.

It has to be noticed that the thermal inertia of a semi-industrial scale combustion facility involves a very slow transient period, in which the time evolution of thermal variables, such as temperatures, depends on many factors, including ambient temperature (variable) or fuel properties (heterogeneous 
blends). The use of this kind of facilities is a challenge to be assumed if representative results of actual boilers are wanted.

According to the data of Tables 1-2, the percentage of moisture is higher for blends (tests 2-8) than for $100 \%$ SAC (test 1). Specifically, the increase with regard to coal combustion ranges from $15 \%$ to $50 \%$ in biomass co-firing tests. As for ash content, it decreases with regard to test 1 for biomass co-firing from a $3.4 \%$ in test 2 , to a $17 \%$ in test 8 . The most relevant changes occur when coal mine waste residues are introduced: moisture undergoes an increase of $100 \%$ and $170 \%$ and ash content of $90 \%$ and $136 \%$ for tests 9 and 10, respectively.

In the table, flue gas temperature is measured inside the combustion chamber, near the deposition probe, by means of a thermocouple (see location in Figure 1). Before to be used in the thermal model, the measurement is corrected of convection and radiation effects, according to the method of Cox and Chitty reported in Ref. (43). With respect to the refractory wall, the referenced temperature is the mean value inside the first refractory ring, near the throat.

\section{Thermal model}

\subsection{Initial considerations}

The main parts of the deposition probe $\left(x_{1}-x_{3}\right.$ in Figure 2$)$ were discretized in eight control volumes in order to obtain an appropriate compromise between computation time and accuracy of the solution. The section $x_{3}$ includes volumes 1-4, section $x_{2}$ volumes 5-7 and the section $x_{1}$ constitutes the eighth volume. Additionally, a simplified model was developed for sections $x_{4}-x_{5}$ to estimate the actual temperatures of cooling air arriving and leaving the combustion chamber.

Heat transfer coefficients by convection inside the probe were calculated according to the Gnielinski correlation, including corrections for entry effects (44) and Stephan correction for the annular duct (45). The convection coefficient over the outer surface of the probe due to the combustion gases was estimated according to the Churchill and Bernstein correlation (44).

Emissivity and absorptivity of flue gases were estimated from the Hottel's model (44; 46), considering the approach of gray gas for each component of a mixture of water, carbon dioxide and non-participating gases. The partial pressure for each gas was calculated from the mass balance under complete combustion conditions. In order to carry out the presence of soot particles, a corrective factor is applied (47):

$$
\epsilon=1-\left(1-\epsilon_{c w}\right) \exp \left(-K C_{s} D_{c h} T_{g}\right)
$$


where $K$ is a dimensional constant $\left(1.5 \cdot 10^{-3} \mathrm{~m}^{2} / \mathrm{g} \mathrm{K}\right), C_{s}$ is the particle concentration $\left(\mathrm{g} / \mathrm{m}^{3}\right), D_{c h}$ is the inner diameter of the combustion chamber $(\mathrm{m})$ and $\epsilon_{c w}$ is the emissivity before correction.

Values for the properties used in the thermal model are gathered in Table 3. Emissivity of the different radiative surfaces has been considered near to unity (29), while typical values of thermal conductivity for the stainless-steel ducts (44) and of the particle concentration factor (47) have been considered. Given the uncertainty in those values, a sensitivity analysis is performed in Section 4 in order to evaluate the influence of these estimated properties and the order of magnitude of deviations in subsequent calculations.

\begin{tabular}{llc} 
Table 3: Values of some properties used in the thermal model. \\
\hline Thermal property & Symbol & Value \\
\hline & & \\
Ducts conductivity $(\mathrm{W} / \mathrm{m}-\mathrm{K})$ & $\kappa_{\text {tube }}$ & 20 \\
Thermocouple emissivity & $\epsilon_{t h}$ & 0.8 \\
Emissivity of surfaces $1 / 2$ & $\epsilon_{1 / 2}$ & 0.9 \\
Emissivity of outer surface & $\epsilon_{s}$ & 0.9 \\
Emissivity of water walls & $\epsilon_{w}$ & 1 \\
Particle concentration $\left(\mathrm{g} / \mathrm{m}^{3}\right)$ & $C_{s}$ & 0.6 \\
\hline
\end{tabular}

\subsection{Radiative exchange model}

Conventional models usually simulate the radiative exchange between a single surface and the flame (35). However, given the proximity of water cooling walls to the deposition probe, a better approach is here considered with two sink surfaces and a gaseous source, according to the delta radiation network of Figure 3 (48). The magnitudes referred to probe, wall and gases are denoted with the subscripts $s, w$ and $g$, respectively. According to the actual geometry, the resistances are:

$$
\begin{aligned}
& R_{k}=\frac{1-\epsilon_{k}}{\epsilon_{k} A_{k}} \quad k=w, s \\
& R_{k g}=\frac{1}{A_{k} \epsilon_{g k}} \quad k=w, s \\
& R_{s w}=\frac{1}{A_{s} F_{s w}\left(1-\epsilon_{g s w}\right)}
\end{aligned}
$$



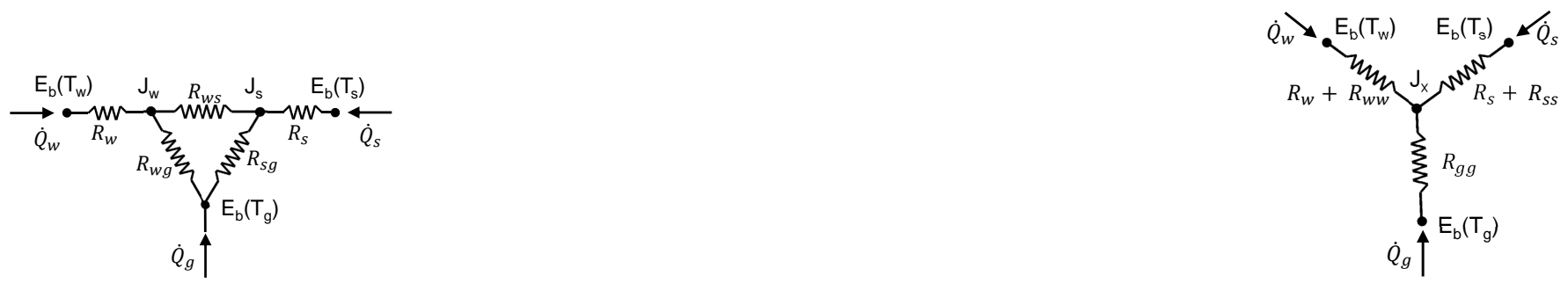

Figure 3: Delta-wye transformation for a model of two surfaces and a gaseous source.

183

where the view factors $F_{w g}$ and $F_{s g}$ are considered near to the unity and $F_{s w}=0.9$ was calculated from the actual geometry. The heat fluxes are:

$$
\dot{Q}_{s w}=\frac{J_{s}-J_{x}}{R_{s w}}, \quad \dot{Q}_{g k}=\frac{\sigma T_{g}^{4}-J_{k}}{R_{k g}} \quad k=w, s
$$

Following the delta-wye transformation, each leg of the wye consists of the surface resistance in series with the resistance found from the transformation:

$$
R_{k k}=\frac{R_{k l} R_{k m}}{R_{k l}+R_{l m}+R_{k m}} \quad k, l, m=w, s, g
$$

being $\delta_{k l}=\delta_{l m}=\delta_{k m}=0$. The corresponding heat fluxes, which will be used in the following section, are given by the following relations:

$$
\begin{aligned}
\dot{Q}_{k} & =\frac{\sigma T_{k}^{4}-J_{x}}{R_{k}+R_{k k}}=\frac{\sigma T_{k}^{4}-J_{k}}{R_{k}} \quad k=s, w \\
\dot{Q}_{g} & =\frac{\sigma T_{g}^{4}-J_{x}}{R_{g g}}
\end{aligned}
$$

where radiosities $\left(J_{k}\right)$ are obtained from the energy balance at the central node.

\subsection{Energy balances}

The model input data, registered during the experimental tests, are combustion and cooling air flow rates, fuel flow rates, flue gas temperature $\left(T_{g}\right)$ and temperature of inlet and outlet of cooling air. The main outputs are the heat absorbed by the cooling air, deposit surface temperature $\left(T_{d}\right)$, probe surfaces temperatures $\left(T_{0-3}\right)$, temperature profile of cooling air across the probe and deposit thermal resistance.

Mass and energy balances are applied to each control volume considering quasi-steady regimen. Given the very small thickness of tube walls, longitudinal heat transfer by conduction through the ducts is considered negligible. 
The energy balance in the deposit surface for control volume $j$-th is:

$$
\begin{aligned}
\dot{Q}_{1, j} & =-\dot{Q}_{s, j}+h_{g, j} A_{d e p, j}\left(T_{g}-T_{d, j}\right) \\
& =\frac{x_{j}\left(T_{d, j}-T_{3, j}\right)}{R_{t, d e p}^{\prime}}
\end{aligned}
$$

where $\dot{Q}_{s, j}$ is the absorbed heat flux by radiation from gases and wall given by Eq. (6), $h_{g, j}$ is the estimated coefficient of heat transfer by convection over the deposit, $T_{d, j}$ is the temperature in the external surface of the deposit given by $A_{d e p, j}$ and the thermal resistance per unit length due to ash deposition is denoted by $R_{t, d e p}^{\prime}$.

For the surfaces 3 and 2 (Figure 2), corresponding to the outer and inner sides of the outer tube of the probe, the energy balances are:

$$
\begin{aligned}
\dot{Q}_{1, j} & =\frac{2 \pi \kappa_{t u b e} x_{j}\left(T_{3, j}-T_{2, j}\right)}{\ln \left(r_{3, j} / r_{2, j}\right)} \\
& =A_{1, j} \sigma \epsilon_{t, j}\left(T_{2, j}^{4}-T_{1, j}^{4}\right)+h_{a, j} A_{2, j}\left(T_{2, j}-\bar{T}_{a, j}\right)
\end{aligned}
$$

where $T_{2, j}$ and $T_{3, j}$ denote the temperature of volume $j$ in the surfaces 2 and $3, \bar{T}_{a, j}$ is the mean bulk temperature of the cooling air inside the annulus and $\epsilon_{t, j}$ is the equivalent emissivity from surface 2 to surface 1, which are coaxial cylinders:

$$
\epsilon_{t, j}=\left(\frac{1}{\epsilon_{1}}+\frac{1-\epsilon_{2}}{\epsilon_{2}} \frac{A_{1, j}}{A_{2, j}}\right)^{-1}
$$

Being air a non-participating medium, the energy balance for the air in the annular duct of the volume $j$-th:

$$
\begin{array}{r}
h_{a, j} A_{2, j}\left(T_{2, j}-\bar{T}_{a, j}\right)=h_{a, j} A_{1, j}\left(\bar{T}_{a, j}-T_{1, j}\right)+ \\
+\dot{m}_{a i r} c p_{a, j}^{a i r}\left(T_{a, j-1}^{a i r}-T_{a, j}^{a i r}\right)
\end{array}
$$

where $c p_{a, j}^{a i r}$ is the specific heat capacity at temperature $\bar{T}_{a, j}$, and $T_{a, j-1}^{a i r}$ and $T_{a, j}^{a i r}$ are the air temperatures at exit and entry of volume $j$-th, respectively, inside the annulus .

The energy balances in surfaces 1 and 0 of inner tube are:

$$
\begin{aligned}
\dot{Q}_{2, j} & =\frac{2 \pi \kappa_{\text {tube }} x_{j}\left(T_{1, j}-T_{0, j}\right)}{\ln \left(r_{1, j} / r_{0, j}\right)} \\
& =A_{1, j} \sigma \epsilon_{t, j}\left(T_{2, j}^{4}-T_{1, j}^{4}\right)+h_{a, j} A_{1, j}\left(\bar{T}_{a, j}-T_{1, j}\right) \\
& =h_{i, j} A_{0, j}\left(T_{0, j}-\bar{T}_{i, j}\right) \\
& =\dot{m}_{\text {air }} c p_{i, j}^{\text {air }}\left(T_{i, j}^{\text {air }}-T_{i, j-1}^{\text {air }}\right)
\end{aligned}
$$




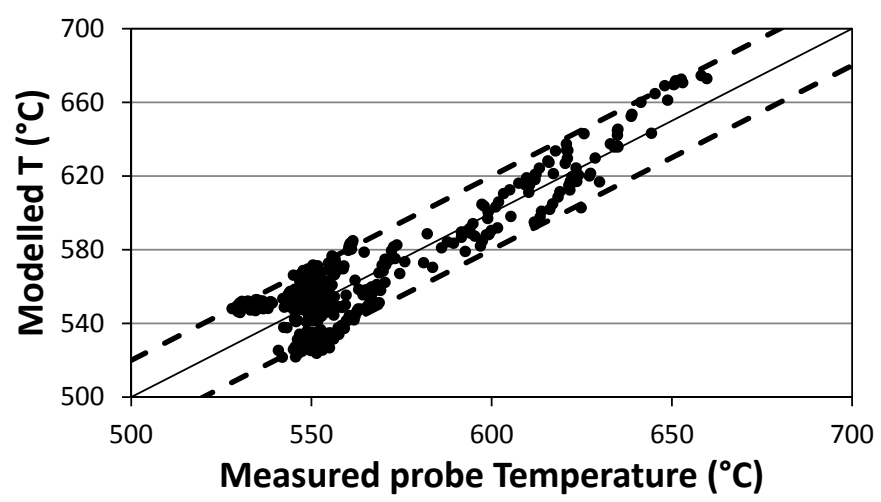

Figure 4: Predicted temperature vs. measured temperature of probe surface at the point indicated in Figure 2 during the tests 1-10. The full line represents zero error, while dashed lines indicates deviations of $\pm 20^{\circ} \mathrm{C}$.

where $c p_{i, j}^{a i r}$ is the specific heat capacity at temperature $\bar{T}_{i, j}, T_{1, j}$ and $T_{0, j}$ are surface temperatures of inner duct and $T_{i, j}^{a i r}$ and $T_{i, j-1}^{a i r}$ are the air temperatures at exit and entry of volume $j$-th, respectively, inside the inner tube.

Finally, the heat uptake is given by:

$$
\begin{aligned}
\dot{Q} & =-\sum_{j} \dot{Q}_{s, j}=\dot{m}_{a i r} \sum_{j} c p_{i, j}^{a i r}\left(T_{i, j}^{a i r}-T_{i, j-1}^{a i r}\right) \\
& +\dot{m}_{a i r} \sum_{j} c p_{a, j}^{a i r}\left(T_{a, j-1}^{a i r}-T_{a, j}^{a i r}\right)
\end{aligned}
$$

\subsection{Validation of thermal model}

Before the application of the thermal model to compare the thermal resistances, a validation has been carried out with the available experimental data. The probe surface temperature was measured with a thermocouple during combustion tests (see the position in Figure 2) and compared with the output of the model.

Validation data have been selected following two criteria. On the one hand, stable regimen is required as it is a premise for the validity of balance equations considered in the thermal model. Accordingly, the transient period at the begining of the tests has been discarded. On the other hand, high temperature in the refractory wall is desirable, as the radiative exchange model considers thermal equilibrium between flame and refractory wall.

Under such conditions, maximum deviations of around $20^{\circ} \mathrm{C}$ are obtained when the measurement is compared to the calculated temperature with the model at the same point. Figure 4 represents the predicted value of the probe surface temperature vs. the measured value for all the tests with an error range of $\pm 20^{\circ} \mathrm{C}$. It has to be noticed that predictions are in that range even during some 

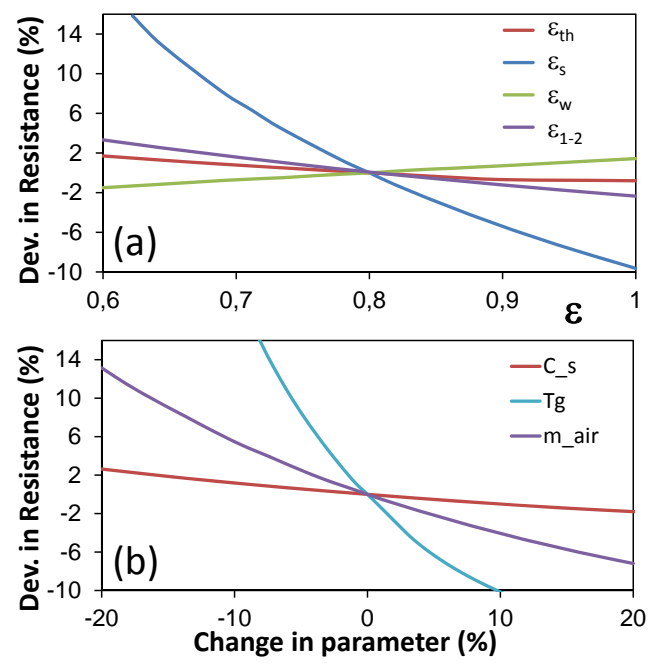

Figure 5: Deviation in thermal resistance of ash deposits under changes in certain parameters.

periods for which surface temperature is far from the set point $\left(550^{\circ} \mathrm{C}\right)$.

The small observed deviations could be due both to the inherent thermocouple errors, to some influential variables in the thermal model, as fouling on chamber walls, ambient temperature or cooling water temperature, which cannot be controlled, or to some assumptions in the thermal model, such as negligible longitudinal heat transfer in the outer pipe.

\section{Results and discussion}

This section gathers the main results of the work, with a practical focus. Firstly, a sensitivity analysis is performed to identify the more influential parameters which might be known or measured to reach accurate enough predictions of thermal resistance. Secondly, heat transfer and thermal resistance are compared for the different co-firing tests. Finally, a realistic discussion about the usefulness and the possibility of thickness prediction is carried out.

\subsection{Influential parameters}

A sensitivity analysis was performed to quantify the dependency of final predictions on variations in certain magnitudes: unknown properties used in the thermal model and operational parameters.

From such analysis, it has been demonstrated that thermal conductivity of pipes, cooling air pressure and total combustion air mass flow produce variations in thermal resistance of ash deposits less than $1 \%$ under changes of a $30 \%$ in the parameter value.

The effect of changing emissivities of different surfaces from 0.6 to 1 is shown in Figure 5a. Deviations below $3 \%$ are obtained for thermocouple surface emissivity $\left(\epsilon_{t h}\right)$, wall surface emissivity 
$\left(\epsilon_{w}\right)$ and emissivities of tube ducts $\left(\epsilon_{1}\right.$ and $\left.\epsilon_{2}\right)$.

On the contrary, emissivity of ash deposit surface $\left(\epsilon_{s}\right)$ is a very influential parameter with deviations of $15 \%$ on thermal resistance. Therefore, experimental measurements should be perfomed to achive accurate predictions. In the present work, it is an unknown parameter which has been estimated from the literature. As the sintering process has little contribution in the present tests (41), a typical value of 0.9 was considered for $\epsilon_{s}(29)$.

The influence of cooling air mass flow is shown in Figure 5b. Typical fluctuations during stable operation are below 5\%, resulting in variations of $4 \%$ in thermal resistance of ash deposit. In principle, the registration of $\dot{m}_{\text {air }}$ would be avoided, considering a mean value for the simulations. Nevertheless, under actual conditions with continuous load changes, the registration of this parameter is required.

As for flue gas temperature, the sensibility analysis demonstrates that is the most important parameter. Measurement errors of $10 \%$ produce deviations above $15 \%$ in thermal resistance of ash deposits. Therefore, an accurate equipment should be desirable to measure flue gas temperature inside the combustion chamber.

Finally, variations of a $20 \%$ on particle concentration $\left(C_{s}\right)$ produce deviations below $3 \%$ on thermal resistance. The measure of this parameter is quite difficult in actual facilities, but the error is acceptable, given the uncertainties in more influential parameters as $\epsilon_{s}$ or $T_{g}$.

\subsection{Heat transfer and thermal resistance}

Nowadays, thermal power plants usually work at variable partial loads, following the instantaneous electrical demand. Therefore, the sole heat transfer study is not enough to decide when a cleaning sequence must be activated. On the contrary, thermal resistance is the key parameter to this end because it provides a quantitative measure of actual fouling and its effect on heat uptake rate.

This section gathers the comparative analysis for the time evolution of heat transfer and thermal resistance, for different fuel blend composition. Flue gas temperature along each experimental tests is also shown in Figure 6 with the same colour code to facilitate the correct interpretation of results.

Subsequent figures represent the instantaneous rate of heat transfer rate related to the initial value $(Q(t) / Q(0))$ and the thermal resistance of ash deposits $\left(R_{t, d e p}^{\prime}\right.$ in $\left.m K / W\right)$. The general trend in all cases is a decrease of heat uptake ratio, coherent with an increase of thermal resistance under increasing flue gas temperatures. However instantaneous increases in heat transfer, associated to fast decrease of thermal resistance, are also observed in many cases. This phenomenon could be caused by spontaneous ash sheddings, as occurrs in actual heat exchangers $(35 ; 36)$. 

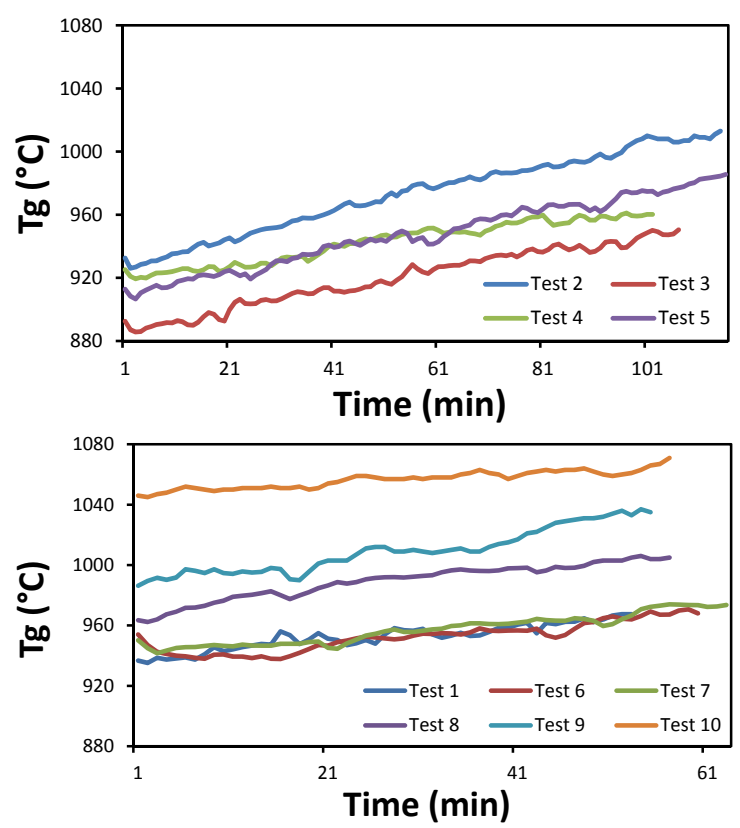

Figure 6: Flue gas temperture registered during experimental tests.
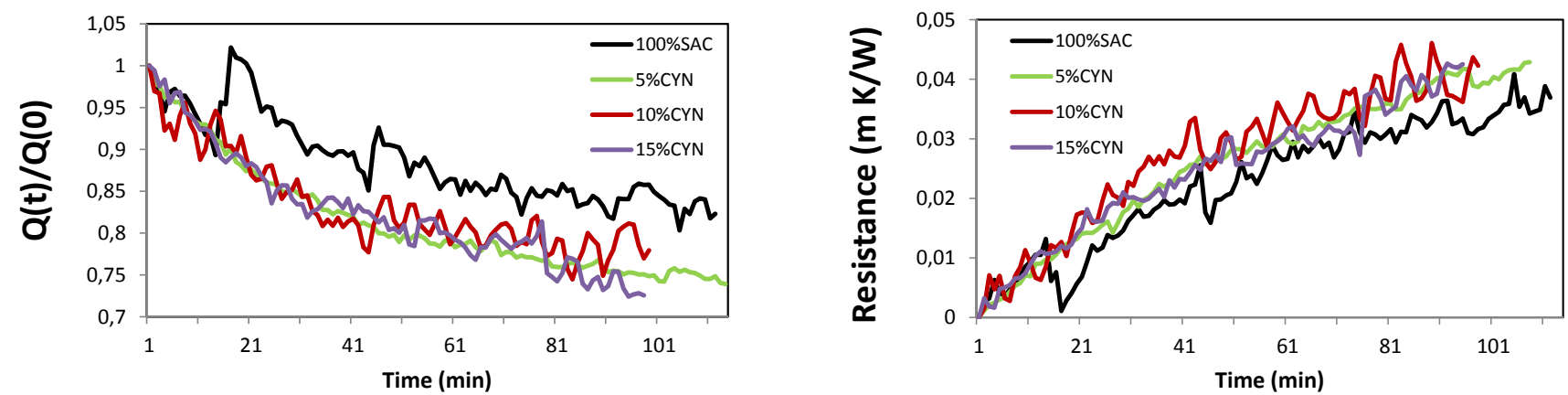

Figure 7: Time evolution of heat uptake ratio (left) and deposit thermal resistance (right) for tests 1-4.
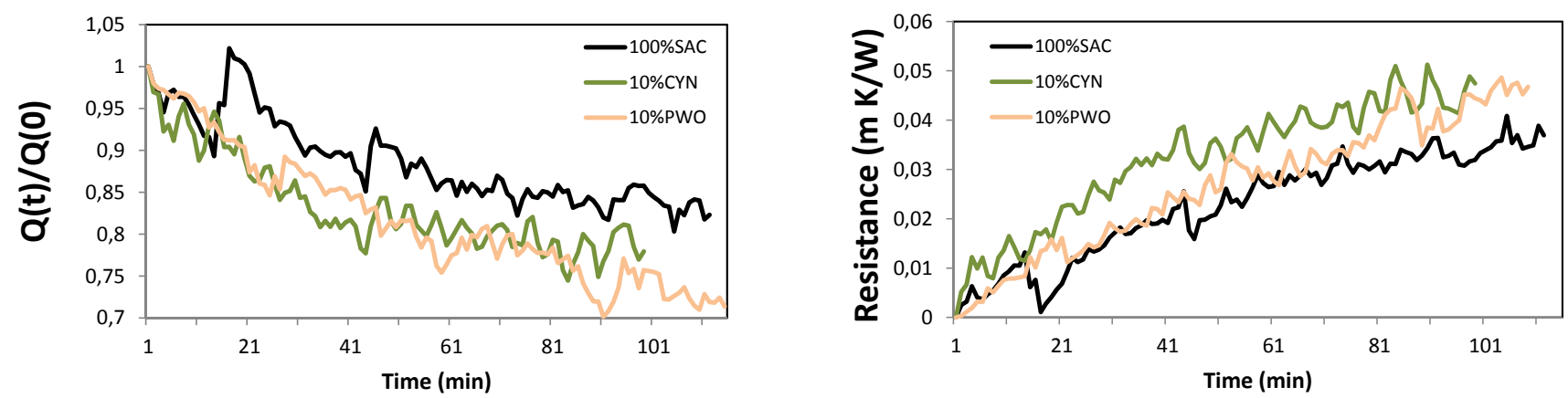

Figure 8: Time evolution of heat uptake ratio (left) and deposit thermal resistance (right) for tests 1, 3 and 5.

Figure 7 compares such variables for tests 1-4, performed under different percentages of CYN. As it could be expected, the fouling rate and the decrease of heat transfer rate are slower for $100 \%$ SAC than during co-firing with CYN. Furthermore, spontaneous sheddings seem to be more frequent for 


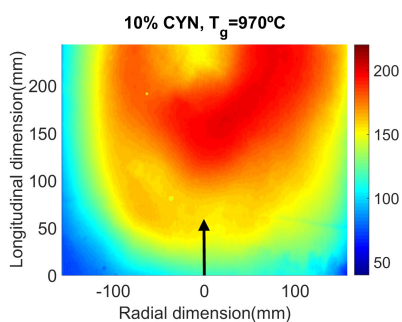

Figure 9: Mean radiation level during co-firing at a gases temperature of $970^{\circ} \mathrm{C}$ and nominal operational conditions. Left: $10 \%$ CYN with $[\mathrm{CO}]=82 \mathrm{mg} / \mathrm{m}^{3} \mathrm{~N}$. Right: $10 \%$ PWO with $[\mathrm{CO}]=460 \mathrm{mg} / \mathrm{m}^{3} \mathrm{~N}$. of $5 \% \mathrm{CYN}$ (test 2) follow very monotonic trend, while many spontaneous sheddings would be identified for 10\%CYN (test 3) and 15\%CYN (test 4). Such different dynamics could be explained from higher temperatures in the first case, which could influence the structure of the deposit, producing higher sintering level and reducing spontaneous shedding of ash deposits. In addition, temperatures would also change the emissivity of the flame as the percentage of CYN increase, due to the higher volatile content (39). Such changes are influential on radiative heat exchange, but they were not considered in the present modelling approach.

Thermal resistance is slightly lower for 10\% CYN than for $15 \%$ CYN as it would be expected, but it is also lower than for $5 \% \mathrm{CYN}$. This result could be explained from higher temperatures during test 2 both, for combustion gases and for refractory walls, and the subsequent absence of casual sheddings because of a more important sintering of the outer deposit layer.

Figure 8 compares the heat transfer ratio and the deposit thermal resistance of tests 1,3 and 5 (100\% SAC, 10\%CYN and 10\%PWO, respectively). As previously, decrease in heat uptake ratio is lower for $100 \%$ SAC, while it is quite similar for the two biomass blends. Thermal resistance is slightly lower for PWO than that for CYN, although they are very similar at the end of the experiment. Despite the small difference in gases temperature, this was a non-expectable result as, a priori, cynara, with much higher ash content, would produce a fouling rate significantly faster.

In order to explain this result, the flame radiation captured by the CCD camera is here used to compare the combustion performance during both tests, given the usefulness of flame imaging to detect instabilities and inefficiencies during combustion shown in previous works (39; 49). Specifically, Figure 9 represents the mean gray level of a flame video constituted by 5200 images, where the burner

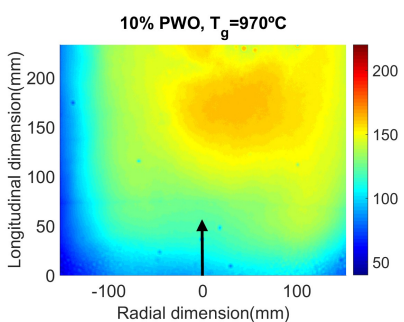

$100 \%$ SAC. In spite of the lower ash content of CYN, the presence of alkaline elements, as calcium or potassium, together with other elements as sulfur and chlorine, favors fouling growth $(37 ; 41)$.

With regard to CYN-SAC blends, some differences in the dynamics would be noticed. Time series 

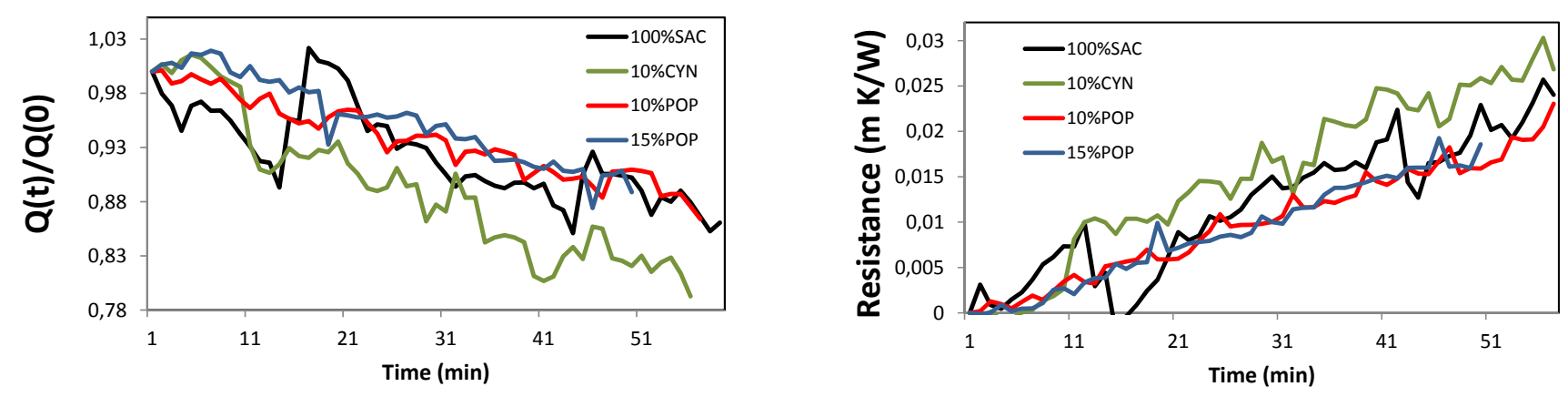

Figure 10: Time evolution of heat transfer ratio (left) and deposit thermal resistance (right) for tests 5-8.
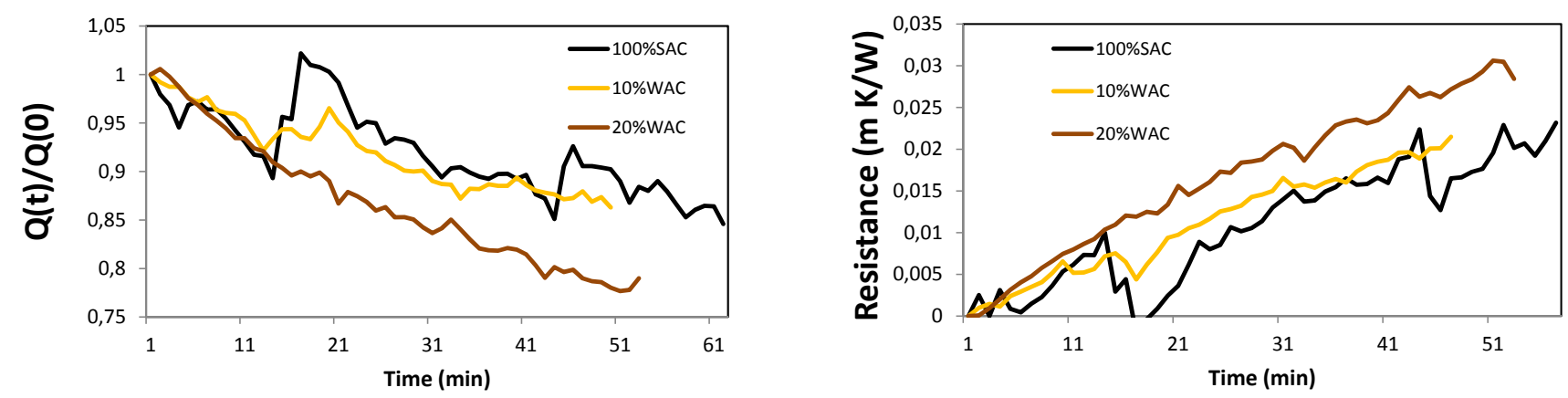

Figure 11: Time evolution of heat transfer ratio (left) and deposit thermal resistance (right) for tests 1 and 9-10.

exit is centered on the bottom side. A lower level of radiation during test 5 and higher emissions of carbon monoxide than those of test 3 were registered (460 vs. $82 \mathrm{mg} / \mathrm{m}^{3} \mathrm{~N}$ ), indicating an inefficient PWO combustion. The probable generation of unburned solids could decrease flame radiation and increase the amount of fouling deposits.

Figure 10 compares results for blends of POP and CYN with 100\%SAC. First of all, little differences are observed between the two blends of POP (tests 7-8), even in spite of the important difference of refractory wall temperatures (Figure 6).

On the contrary, a very different dynamics is observed for tests 1 and 6 (100\%SAC and 10\%CYN, respectively). Both heat uptake ratio and thermal resistance exhibit a very monotonic trend for poplar blends, while a more irregular evolution is observed for $100 \% \mathrm{SAC}$ and $10 \% \mathrm{CYN}$, probably due to alternating periods of fouling and ash sheddings.

Additionally, a lower fouling level is obtained for poplar blends as it was expected from its very low ash content shown in Table 1. Both phenomena could be interrelated. The important reduction in ash content (12\% and 15\% for tests 7 and 8, respectively) would produce a thinner layer of ash deposit, resulting in less probable shedding events.

Finally, Figure 11 compares the time evolution of heat transfer and thermal resistance for SAC 

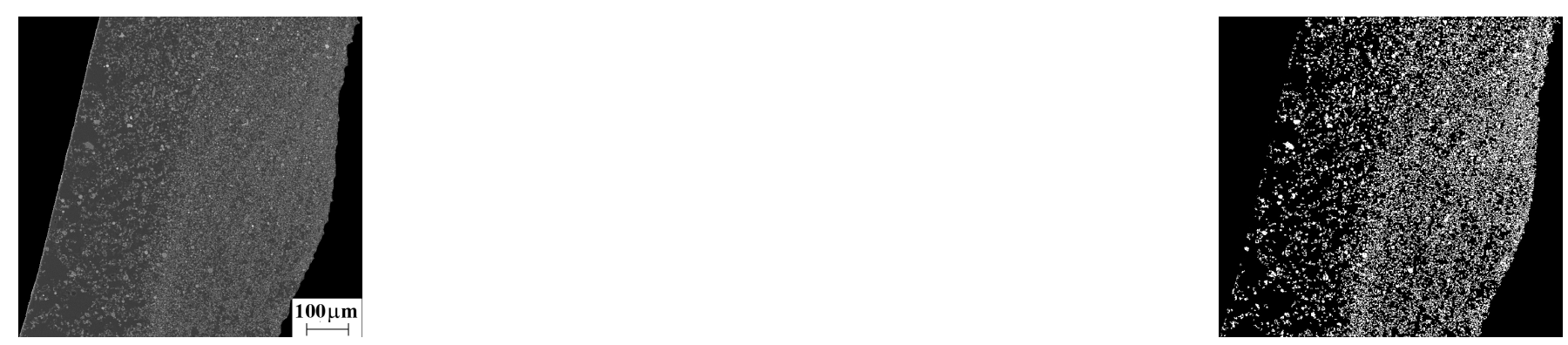

Figure 12: SEM image of a fouling layer during SAC combustion (left) and the corresponding black-white picture (right) for porosity estimation.

(test 1) and CMR (tests 9-10). As occurs with test 2, a very regular decrease of heat uptake is observed during co-firing of CMR (tests 9-10). The absence of spontaneous sheddings could be due to both, very high temperatures during the test, which could produce a more intense sintering, and the very high ash content of CMR (55\% d.b.). Thermal resistance is significantly greater for $20 \%$ CMR, where mass flow of CMR is a $50 \%$ of the total fuel flow rate.

All in all, it would be expected to obtain very much higher fouling levels for coal mine waste residues than for biomass fuels. Two possible phenomena could explain the experimental result of CMR: a lower porosity of the deposit or a continuous loss of ash due to the great concentration of particles impacting with the probe surface. Further experimental research should be done to clarify the cause of the observed behaviour.

\subsection{Discussion about thermal conductivity estimation}

In principle, besides thermal resistance, the prediction of deposits thickness would be desirable. The essential parameter to this end is the thermal conductivity, given the almost linear relation between them. In turn, according to previous works $(26 ; 31 ; 50 ; 51)$, the microstructure, specially the porosity, is determining to properly estimate thermal conductivity. Specifically, Baxter established a linear relation between thermal conductivity and porosity (50), while various authors reported an important influence of sintering degree as deposit growth takes place $(26 ; 31)$.

This section performs a realistic evaluation of thickness prediction under semi-industrial scale conditions. The results about porosity of ash deposits obtained from images acquired with scanning electron microscope (SEM) are presented. The test coupon was embedded in epoxy, and the fouling layer was cross sectioned and polished before the imaging with SEM.

Thresholding method was applied to SEM images in order to convert gray images into black and white pictures. Threshold was adjusted for each image as illumination was different from one to 

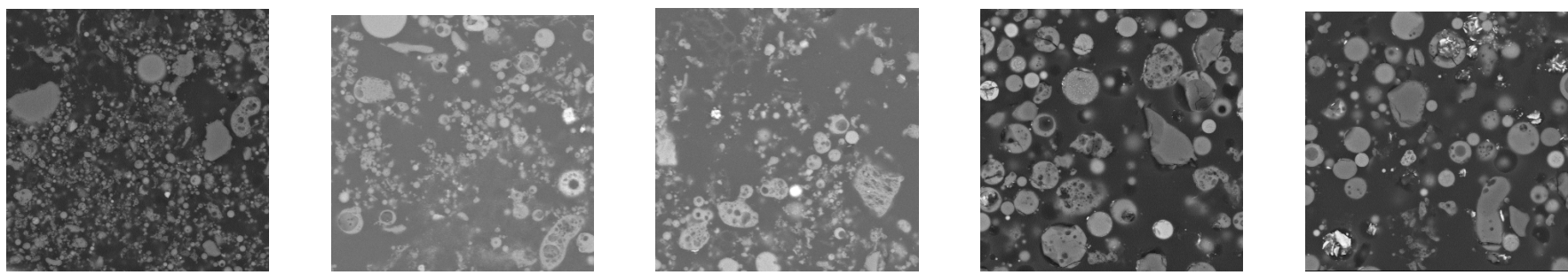

Figure 13: Examples of SEM images of ash deposits used for porosity estimation for different fuel blends. From left to right: Tests $1,3,4,9$ and 10 .

another. An example of the final result is shown in Figure 12, where dark background corresponds to epoxy and bright regions are ash fouling particles. The porosity was determined from the percentage of black pixels in the fouling layer.

A strong decrease of porosity was observed from inner to outer layer of the deposit as can be seen in Figure 12. Specifically, for the deposit collected during 100\% SAC combustion, porosity diminishes from $82 \%$ to $58 \%$. This result agrees with previous observations (26) and could be due to a certain degree of sintering in the outer layer as it is subjected to higher temperatures.

Mean porosity has been estimated for those tests with samples of enough quality (Figure 13). The mean porosity is in all cases within the usual ranges as it is shown in Table 4. Porosity is around $10 \%$ lower for $100 \%$ SAC (test 1) than for blends of CYN and CMR. Little differences were obtained in porosity for CYN blends, while a certain increase from $74 \%$ to $80 \%$ is obtained for CMR.

\begin{tabular}{ccc} 
Table 4: Mean porosity estimated from SEM images \\
\hline Test & Fuel blend & Mean porosity (\%) \\
\hline 1 & $100 \% \mathrm{SAC}$ & 62 \\
3 & $10 \% \mathrm{CYN}$ & 74 \\
4 & $15 \% \mathrm{CYN}$ & 72 \\
9 & $10 \% \mathrm{CMR}$ & 74 \\
10 & $20 \% \mathrm{CMR}$ & 80 \\
\hline
\end{tabular}

According to previous works $(31 ; 34)$, changes of the observed order in porosity could double the value of thermal conductivity. For this reason, the prediction of thickness is almost impossible during operation of actual boilers and dedicated and sophisticated instruments should be installed. However, for the design of cleaning sequences in superheaters, the thickness value itself is not essential and the prediction of fouling thermal resistance would be enough in most cases $(35 ; 36)$. 


\section{Summary and conclusions}

The present work has presented the results about ash deposition during successful co-firing of South African coal with three biomasses and with coal mine waste residues. An instrumented deposition probe, installed in a semi-industrial scale facility, emulated the conditions of actual superheaters in power stations.

A thermal model of the deposition probe was developed for estimation of deposit thermal resistance by considering two sink surfaces and a gaseous mass source in the radiative exchange model. The validation was performed by comparing the predicted and the measured temperature of the probe surface. Maximum deviations of $20^{\circ} \mathrm{C}$ were obtained, being considered an acceptable figure for the present approach, given the order of magnitude of typical errors in thermocouples under convective and radiative effects.

The most influential parameters on thermal resistance were identified from a sensitivity analysis: the emissivity of deposit surface and the flue gas temperature. Therefore, the measure of emissivity under the specific conditions of final application and the registration of the flue gas temperature with high accuracy during the tests are mandatory to achive an accurate prediction of fouling thermal resistance.

The comparison of time evolution of heat transfer ratio and thermal resistance for different fuel blends indicated that the introduction of cynara and pine increases the fouling rates, even for low substitution percentages. On the contrary, the introduction of poplar, with a very low ash content, produces lower or very similar levels of fouling rate to that obtained for coal combustion (41). With regard to coal mine waste residues, given its very high ash content, an important worsening with regard to deposit thermal resistance would be expected, but the calculated value was similar to that obtained for cynara and further research must be done to clarify such experimental result.

Finally, a discussion about the estimation of thermal conductivity estimation was performed from experimental data extracted from SEM images. On the one hand, fuel blends gave rise to higher porosity, related to lower thermal conductivity, especially for coal mine waste residues. On the other hand, the analysis on microstructure confirmed that porosity, and therefore thermal conductivity, varies from inner to outer layers (26). Thus, under real conditions, it is not possible to predict the deposit thickness with enough accuracy and dedicated and customized instruments should be designed and installed for its measurement in every particular facility if thickness is needed.

In summary, besides the interest of the comparative study of experimental results during co-firing 
of the different fuel blends, the paper has demonstrated the usefulness of thermal models to estimate the thermal resistance of ash deposits without the need of sophisticated instrumentation. Dedicated thermal models, similar to the developed one, could be integrated in the control of combustion facilities in order to design smart cleaning sequences.

Acknowledgements This work was partially financed by the projects ENE2013-48003-R and IPT-2012-0251-120000 (Spanish Ministry of Economy and Competitiveness, R\&D Program). The authors wish to thank to O. Puyo, C. Chuansheng and D. Plaza for their support and help during the experimental tests.

\section{Bibliography}

[1] L. Zhang, C. C. Xu, P. Champagne, Overview of recent advances in thermo-chemical conversion of biomass, Energ. Convers. Manage. 51 (5) (2010) 969-982.

[2] R. Saidur, E. A. Abdelaziz, A. Demirbas, M. S. Hossain, S. Mekhilef, A review on biomass as a fuel for boilers, Renew. Sust. Energ. Rev. 15 (5) (2011) 2262-2289.

[3] A. Williams, J. M. Jones, L. Ma, M. Pourkashanian, Pollutants from the combustion of solid biomass fuels, metering 39 (SI) (2012) 403-412, Conference and Exhibition on Biomass for Energy (World Bioenergy), Jonkoping, Sweden, May 29-31, 2012.

[4] IEA-ETSAP, IRENA, Biomass co-firing: Technology brief e21, Technical report (2013).

[5] Y. Zhang, Z. Zhang, M. Zhu, F. Cheng, D. Zhang, Interactions of coal gangue and pine sawdust during combustion of their blends studied using differential thermogravimetric analysis, Biores. Technol. 214 (2016) 396-403. doi:10.1016/j.biortech.2016.04.125.

[6] A. Zbogar, F. Frandsen, P. Jensen, P. Glarborg, Heat transfer in ash deposits: A modelling tool-box, Prog. Energ. Combust. Sci. 31 (5-6) (2005) 371-421.

[7] I. Barnes, Slagging and fouling in coal-fired boilers, IEA coal research report no. CCC/147 (2009). 
[8] L. Baxter, Biomass-coal co-combustion: opportunity for affordable renewable energy, Fuel 84 (10) (2005) 1295-1302, International Symposium on Utilisation of Coal and Biomass, Newcastle, Australia, Sep 28-29, 2003.

[9] F. Frandsen, Utilizing biomass and waste for power production - a decade of contributing to the understanding, interpretation and analysis of deposits and corrosion products, Fuel 84 (10) (2005) 1277-1294, International Symposium on Utilisation of Coal and Biomass, Newcastle, Australia, Sep 28-29, 2003.

[10] Y. Shao, C. C. Xu, J. Zhu, F. Preto, J. Wang, G. Tourigny, C. Badour, H. Li, Ash Deposition during Co-firing Biomass and Coal in a Fluidized-Bed Combustor, Energ. Fuel. 24 (2010) 46814688.

[11] M. U. Degereji, D. B. Ingham, L. Ma, M. Pourkashanian, A. Williams, Prediction of ash slagging propensity in a pulverized coal combustion furnace, Fuel 101 (2012) 171-178. doi:10.1016/j.fuel.2010.12.038.

[12] M. U. Garba, D. B. Ingham, L. Ma, M. U. Degereji, M. Pourkashanian, A. Williams, Modelling of deposit formation and sintering for the co-combustion of coal with biomass, Fuel 113 (2013) 863-872. doi:10.1016/j.fuel.2012.12.065.

[13] L. De Fusco, A. Boucquey, J. Blondeau, H. Jeanmart, F. Contino, Fouling propensity of high-phosphorus solid fuels: Predictive criteria and ash deposits characterisation of sunflower hulls with $\mathrm{P} /$ Ca-additives in a drop tube furnace, Fuel 170 (2016) 16-26. doi:10.1016/j.fuel.2015.12.017.

[14] S. Zheng, X. Zeng, C. Qi, H. Zhou, Modeling of ash deposition in a pulverized-coal boiler by direct simulation Monte Carlo method, Fuel 184 (2016) 604-612. doi:10.1016/j.fuel.2016.07.058.

[15] P. Venturini, D. Borello, C. Iossa, D. Lentini, F. Rispoli, Modeling of multiphase combustion and deposit formation in a biomass-fed furnace, Energy 35 (7) (2010) 3008-3021. doi:10.1016/j.energy.2010.03.038.

[16] M. Losurdo, H. Spliethoff, J. Kiel, Ash deposition modeling using a visco-elastic approach, Fuel 102 (2012) 145-155. doi:10.1016/j.fuel.2012.04.047. 
[17] K. Waclawiak, S. Kalisz, A practical numerical approach for prediction of particulate fouling in PC boilers, Fuel 97 (2012) 38-48. doi:10.1016/j.fuel.2012.02.007.

[18] B. Kreutzkam, C. Wieland, H. Spliethoff, Improved numerical prediction of ash formation and deposition using a novel developed char fragmentation model, Fuel 98 (2012) 103-110. doi:10.1016/j.fuel.2012.02.056.

[19] C. Wieland, B. Kreutzkam, G. Balan, H. Spliethoff, Evaluation, comparison and validation of deposition criteria for numerical simulation of slagging, Applied Energy 93 (2012) 184-192.

[20] R. Weber, M. Mancini, N. Schaffel-Mancini, T. Kupka, On predicting the ash behaviour using Computational Fluid Dynamics, Fuel Process. Technol. 105 (SI) (2013) 113-128. doi:10.1016/j.fuproc.2011.09.008.

[21] A. M. Beckmann, M. Mancini, R. Weber, S. Seebold, M. Mueller, Measurements and CFD modeling of a pulverized coal flame with emphasis on ash deposition, Fuel 167 (2016) 168-179. doi:10.1016/j.fuel.2015.11.043.

[22] S. R. Gubba, D. B. Ingham, K. J. Larsen, L. Ma, M. Pourkashanian, H. Z. Tan, A. Williams, H. Zhou, Numerical modelling of the co-firing of pulverised coal and straw in a 300 MWe tangentially fired boiler, Fuel Process. Technol. 104 (2012) 181-188. doi:10.1016/j.fuproc.2012.05.011.

[23] T. Wall, S. Bhattacharya, L. Baxter, G. Richards, J. Harb, The character of ash deposits and the thermal performance of furnaces, Fuel Process.Technol. 44 (1-3) (1995) 143-153.

[24] D. P. Cundick, R. D. Maynes, T. J. Moore, D. R. Tree, M. R. Jones, L. L. Baxter, In situ measurements of the spectral emittance of coal ash deposits, Proceed. ASME Int. Mech. Engin. Congress Exp. 4 (12) (2012) 041002.

[25] A. Brink, D. Lindberg, M. Hupa, M. E. de Tejada, M. Paneru, J. Maier, G. Scheffknecht, A. Pranzitelli, M. Pourkashanian, A temperature-history based model for the sticking probability of impacting pulverized coal ash particles, Fuel Process. Technol. 141 (2, SI) (2016) 210-215. doi:10.1016/j.fuproc.2015.08.039.

[26] M. S. Abd-Elhady, S. H. Clevers, T. N. G. Adriaans, C. C. M. Rindt, J. G. Wijers, A. A. van Steenhoven, Influence of sintering on the growth rate of particulate fouling layers, Int. J. Heat Mass Tran. 50 (1-2) (2007) 196-207. 
[27] K. Laursen, F. Frandsen, O. Larsen, Ash deposition trials at three power stations in Denmark, Energ. Fuel. 12 (2) (1998) 429-442.

[28] H. Wang, J. West, J. Harb, Microanalytical characterization of slagging deposits from a pilotscale combustor, Energ. Fuel. 13 (3) (1999) 570-578.

[29] A. Robinson, S. Buckley, L. Baxter, Experimental measurements of the thermal conductivity of ash deposits: Part 1. Measurement technique, Energ. Fuel. 15 (1) (2001) 66-74.

[30] H. L. Wee, H. Wu, D.-k. Zhang, Heterogeneity of ash deposits formed in a utility boiler during PF combustion, Energ. Fuel. 21 (2) (2007) 441-450.

[31] A. Robinson, S. Buckley, L. Baxter, In situ measurements of the thermal conductivity of ash deposits, in: Burgess, AR and Dryer, FL (Ed.), Twenty-Seventh Symposium (International) on Combustion, vols 1-2, 1998, pp. 1727-1735.

[32] A. Robinson, S. Buckley, N. Yang, L. Baxter, Experimental measurements of the thermal conductivity of ash deposits: Part 2. Effects of sintering and deposit microstructure, Energ. Fuel. 15 (1) (2001) 75-84.

[33] S. Grahl, M. Beckmann, In-situ analysis of deposit properties in steam generators, Int. J. Therm. Sci. 72 (2013) 172-183.

[34] H. Zhou, B. Zhou, L. Li, H. Zhang, Experimental Measurement of the Effective Thermal Conductivity of Ash Deposit for High Sodium Coal (Zhun Dong Coal) in a 300 KW Test Furnace, Energ. Fuel. 27 (11) (2013) 7008-7022.

[35] B. Peña, E. Teruel, L. Díez, Soft-computing models for soot-blowing optimization in coal-fired utility boilers, Appl. Soft Comput. 11 (2011) 1657-1668.

[36] B. Peña, E. Teruel, L. Díez, Towards soot-blowing optimization in superheaters, Appl. Therm. Eng. 61 (2013) 737-746.

[37] C. Bartolomé, A. Gil, I. Ramos, Ash deposition behavior of cynara-coal blends in a PF pilot furnace, Fuel Process. Technol. 91 (11) (2010) 1576-1584. 
[38] E. Teruel, I. Ramos, M. Gil, Pulverised fuel feeding for co-firing based on loss-in-weight flow metering, Biomass Bioenerg. 39 (SI) (2012) 403-412, Conference and Exhibition on Biomass for Energy (World Bioenergy), Jonkoping, Sweden, May 29-31, 2012.

[39] A. González-Cencerrado, B. Peña, A. Gil, Experimental analysis of biomass co-firing flames in a pulverized fuel swirl burner using a CCD based visualization system, Fuel Process. Technol. 130 (2015) 299-310.

[40] A. González-Cencerrado, B. Peña, A. Gil, Coal flame characterization by means of digital image processing in a semi-industrial scale PF swirl burner, Appl. Energ. (2012) 375-384.

[41] C. Bartolomé, A. Gil, Ash Deposition and Fouling Tendency of Two Energy Crops (Cynara and Poplar) and a Forest Residue (Pine Chips) Co-fired with Coal in a Pulverized Fuel Pilot Plant, Energ. Fuel. 27 (10) (2013) 5878-5889.

[42] C. Bartolomé, I. Ramos, A. Gil, Ash deposition in co-firing using cynara biomass residues with coal in a PF pilot plant, in: Proceedings of the $17^{\text {th }}$ European Biomass Conference, 2009, pp. $1230-1237$.

[43] J. Dupuy, J. Maréchal, M. D., Fires from a cylindrical forest fuel burner: combustion dynamics and flame properties, Combust. Flame 135 (2003) 65-76.

[44] Y. Çengel, Heat Transfer, McGraw Hill, 2004.

[45] K. Stephan, Wärmeüberbergang bei turbulenter und bei laminarer strömung in ringspalten, Chem. Ing. Technik 34 (1962) 207-212.

[46] H. C. Hottel, Radiant Heat Transmission, McGraw Hill, 1954.

[47] B. Solvang, E. Naess, A model for temperature measurements errors in off-gas channels, The twelfth international ferroalloys congress, Helsinki, Finland (2010) 89-97.

[48] VDI-Verlag Gmbh, Heat exchanger design handbook, Hemisphere publishing corporation, 1983.

[49] A. González-Cencerrado, B. Peña, A. Gil, Characterization of PF flames under different swirl conditions based on visualization systems, Fuel (2013) 798-809.

[50] L. Baxter, Infuence of ash deposit chemistry and structure on physical and transport properties, Fuel Process. Technol. 56 (1998) 81-88. 
[51] S. Kweon, E. Ramer, A. Robinson, Measurement and simulation of ash deposit microstructure, Energ. Fuel. 17 (5) (2003) 1311-1323. 